\title{
Dual inhibitor of PI3K and mTOR (NVP-BEZ235) augments the efficacy of fluorouracil on gastric cancer chemotherapy
}

This article was published in the following Dove Press journal:

OncoTargets and Therapy

Liangqing Li

Shengwei Zhang

Diya Xie

Hui Chen

Xuelan Zheng

Dun Pan

Department of Gastrointestinal Surgery, The First Affiliated Hospital of Fujian Medical University,

Fuzhou 350005, China
Correspondence: Dun Pan

Department of Gastrointestinal Surgery,

The First Affiliated Hospital of Fujian

Medical University, Fuzhou 350005, China

Tel +86 I38 606I 7622

Email pandun0220@fjmu.edu.cn
Purpose: NVP-BEZ235 is a recently developed dual inhibitor of PI3K and mTOR and shows good inhibitory effects on several types of tumors. However, the efficacy of NVP-BEZ235 on gastric cancer therapy remains unclear. This study aimed to investigate the potential of NVPBEZ235 as a new agent to enhance chemotherapy for gastric cancer.

Methods: Human gastric cancer MKN-45 cells or nude mice xenografted with MKN-45 cells were treated by NVP-BEZ235 and fluorouracil (5-FU) alone or in combination. The proliferation, invasion, apoptosis, and chemoresistance of gastric cancer cells were examined in vivo and in vitro.

Results: In vitro, combined treatment with NVP-BEZ235 and 5-FU showed synergistic inhibitory effects on proliferation, migration, and invasion and synergistic stimulating effects on apoptosis of MKN-45 cells. In vivo, NVP-BEZ235 and 5-FU synergistically inhibited the growth and induced apoptosis of MKN-45 xenografts. Mechanistically, NVP-BEZ235 inhibited $\mathrm{PI} 3 \mathrm{~K} / \mathrm{Akt} / \mathrm{mTOR}$ signaling; decreased the levels of Bcl-2, MMP9, and VEGF; but increased the levels of Bax and cleaved caspase-3 in MKN-45 xenografts.

Conclusion: NVP-BEZ235 enhances the antitumor efficacy of 5-FU. Therefore, NVP-BEZ235 is a promising agent to enhance chemotherapy for gastric cancer.

Keywords: NVP-BEZ235, fluorouracil, gastric cancer, chemotherapy, P13K, mTOR

\section{Introduction}

Gastric cancer is a malignant tumor derived from the epithelium of gastric mucosa, and its mortality ranks second in all mortality due to malignant tumors. There are approximately 100 million new cases of gastric cancer and nearly 800,000 cases of gastric cancer-related deaths in the world annually; thus, gastric cancer is a serious threat to public health. ${ }^{1}$ The main treatment approaches for gastric cancer include surgical resection and chemotherapy; however, the 5-year survival rate of advanced gastric cancer is only $20 \%-30 \% .^{2}$ The main causes of treatment failure for gastric cancer include a high rate of postoperative recurrence and metastasis, resistance to current chemotherapy regimens, and toxic side effects. In recent years, targeted therapy in the comprehensive treatment of tumors has shown some advantages and increasingly received attention. ${ }^{3}$

Targeted therapy focuses on certain key molecules that are overexpressed in tumor cells, with targeted selection of blockers for these molecules. Targeted therapy specifically and efficiently intervenes with signal transduction pathways, which are crucially involved in the occurrence and development of tumors, and demonstrates some advantages such as targeted therapy, low toxic response, and high efficacy (c) hereby accept the Terms. Non-commercial uses of the work are permitted without any further permission from Dove Medical Press Limited, provided the work is properly attributed. For permission for commercial use of this work, please see paragraphs 4.2 and 5 of our Terms (https://www.dovepress.com/terms.php). 
of treatment. PI3K/Akt/mTOR is an important intracellular signal pathway that plays an important role in the regulation of proliferation, differentiation, apoptosis, and invasion of malignant tumor cells. ${ }^{4}$ A preliminary clinical study using PI3K inhibitors wortmannin and LY294002 showed that the inhibition of PI3K/Akt/mTOR signaling may be an effective anticancer therapy. ${ }^{5,6}$ However, lack of selectivity, poor solubility, and instability limit the clinical application of these inhibitors. ${ }^{7}$ In addition, the activation of other pathways resulted in a certain limitation to the therapeutic effects of these inhibitors. ${ }^{8}$ NVP-BEZ235 is a recently developed dual inhibitor of PI3K and mTOR that can inhibit PI3K, mTORC1, mTORC2, and also has shown good inhibitory effects on breast cancer, ovarian cancer, and blood tumors. ${ }^{9,10}$ In addition, NVP-BEZ235 enhanced the inhibitory efficacy of gemcitabine on pancreatic cancer. ${ }^{11}$ However, the efficacy of NVP-BEZ235 on gastric cancer remains unclear. In this study, we aimed to investigate the potential of NVP-BEZ235 as a new agent to enhance chemotherapy for gastric cancer. We examined the effects of NVP-BEZ235 on the proliferation, invasion, metastasis, apoptosis, and chemoresistance of gastric cancer cells in vivo and in vitro.

\section{Materials and methods Reagents}

NVP-BEZ235 and fluorouracil (5-FU) were purchased from MedChenmExpress (Monmouth Junction, NJ, USA); antibodies against Akt, phospho-Akt (Thr308), cleaved caspase-3, mTOR, Bcl-2, Bax, and p62 were purchased from Cell Signaling Technology (Danvers, MA, USA); antibodies against LC3, MMP9, VEGF, and PTEN were purchased from Abcam (Cambridge, UK). $\beta$-actin antibody and horseradish peroxidase (HRP)-coupled goat anti-mouse or goat anti-rabbit antibody were purchased from Lulong Biotech (Xiamen, China).

\section{Cell culture and treatment}

Cells of the human gastric cancer cell line MKN-45 was purchased from the American Type Culture Collection (Manassas, VA, USA), and cultured in RPMI medium supplemented with $10 \%$ fetal bovine serum, $100 \mathrm{U} / \mathrm{mL}$ penicillin, and $0.1 \mathrm{mg} / \mathrm{mL}$ streptomycin at $37^{\circ} \mathrm{C}$ in a $5 \%$ carbon dioxide-saturated humid incubator. The cells were divided into different groups for different drug treatments: control group (only RPMI medium); NVP-BEZ235 group (0.4 $\mu \mathrm{M}$ NVP-BEZ235 diluted in RPMI medium); 5-FU group ( $80 \mu \mathrm{M} 5$-FU diluted in RPMI medium), and combined group $(0.4 \mu \mathrm{M}$ NVP-BEZ235 and $80 \mu \mathrm{M} 5-\mathrm{FU}$ diluted in RPMI medium).

\section{MTT assay}

Cells were seeded into 96-well culture plates at a density of 4,000 cells/well, and cultured in a humidified chamber at $37^{\circ} \mathrm{C}$ overnight. Next, the cells were treated with $0.4 \mu \mathrm{M}$ NVPBEZ235 and/or $80 \mu \mathrm{M} 5$-FU for 24 or 48 hours. Then, $15 \mu \mathrm{L}$ MTT (3 mg/mL Sigma-Aldrich, St. Louis, MO, USA) solution was added to each well in 96-well plates and the plates were incubated at $37^{\circ} \mathrm{C}$ for 4 hours; thereafter, $200 \mu \mathrm{L}$ dimethyl sulfoxide was added to each well in 96-well plates and the absorption value was read at $490 \mathrm{~nm}$ on a microplate reader.

\section{Flow cytometry}

Apoptotic cells were quantified after Annexin-V-fluorescein isothiocyanate (FITC)/propidium iodide (PI) staining. Briefly, after 24-hour drug treatment, different groups of cells were collected, washed with PBS twice, and resuspended for staining using the Annexin-V-FITC/PI kit (BD Biosciences, Franklin Lakes, NJ, USA) in the dark according to the manufacturer's protocols. The samples were analyzed on a flow cytometer immediately.

\section{Cell invasion and migration assay}

Cells in the logarithmic growth phase were starved for 24 hours in serum-free medium, mixed with different drugs, and then added to the upper chamber of a Transwell precoated with Matrigel (Merck Millipore, Germany), whereas RPMI medium supplemented with $10 \%$ BSA was added to the lower chamber. After incubation at $37^{\circ} \mathrm{C}$ for 24 hours, the cells on the upper surface of the filters were wiped by cotton swabs and the cells on the underside of the filters were fixed, stained with crystal violet, and observed under a microscope. In vitro migration assay was conducted similarly as an invasion assay except that the upper chamber was not pre-coated with Matrigel.

\section{Western blotting analysis}

After different drug treatments for 24 hours, the cells were collected and total protein was isolated and quantitated by the bicinchoninic acid (BCA) method. Equal amounts of protein were separated by SDS-PAGE and transferred to polyvinylidene difluoride membranes, which were then incubated with primary antibodies at $4^{\circ} \mathrm{C}$ overnight, and later incubated with secondary antibodies at $37^{\circ} \mathrm{C}$ for 2 hours. The membranes were exposed using the electrochemiluminescence method and the blots were analyzed using ImageJ software.

\section{Nude mouse model}

All animal experiments were conducted under approved protocols of the Animal Care and Use Committee of 
Fujian Medical University and were approved by the same committee. BALB/C nude mice (4-5 weeks old, average weight 16-20 g) were provided by Fuzhou Wu Animal Center (Fuzhou, China). MKN-45 cells in logarithmic growth phase were resuspended in PBS at $2.5 \times 10^{7}$ cells $/ \mathrm{mL}$, and 0.2 $\mathrm{mL}$ was inoculated into the right forelimb armpit of each nude mouse. The mice were randomly divided into four groups $(n=6)$ : the control group received an intraperitoneal injection of saline at $0.02 \mathrm{~mL} / \mathrm{g}$ every 3 days; the $5-\mathrm{FU}$ group received an intraperitoneal injection of 5-FU 0.025 $\mathrm{mg} / \mathrm{g}$ every 3 days; the BEZ235 group received an intraperitoneal injection of BEZ235 $0.04 \mathrm{mg} / \mathrm{g}$ every 3 days; and the combined drug group received an intraperitoneal injection of BEZ235 $0.04 \mathrm{mg} / \mathrm{g}$ and 5-FU $0.025 \mathrm{mg} / \mathrm{g}$ every 3 days. The diet, activity, and mental state of nude mice were observed daily after drug administration. The tumor weight and size of nude mice were recorded twice a week. Thirty days later, the nude mice were sacrificed and the tumors were dissected.

\section{Statistical analysis}

Data were analyzed using the SPSS 18.0 statistical analysis package (SPSS Inc., Chicago, IL, USA). The experimental results were expressed as mean $\pm \mathrm{SD}$, and the data from two groups were compared by the Student's $t$-test and the data among multiple groups were analyzed by one-way ANOVA, $P<0.05$ was considered statistically significant.

\section{Results}

\section{NVP-BEZ235 and 5-FU inhibit the proliferation of MKN-45 cells}

Based on our preliminary results (data not shown), we selected $0.4 \mu \mathrm{M}$ NVP-BEZ235 and/or $80 \mu \mathrm{M} 5$-FU as the dose for the treatment of MKN-45 cells. By the MTT assay, we found that the inhibition rate of the proliferation of MKN-45 cells was $32.70 \% \pm 2.61 \%$ in the NVP-BEZ235 group, $38.17 \% \pm 5.49 \%$ in the 5 -FU group, and $53.87 \% \pm 5.43 \%$ in the combined group after treatment for 24 hours; moreover, the inhibition rate of the proliferation of MKN-45 cells was $58.62 \% \pm 8.53 \%$ in the NVP-BEZ235 group, $44.83 \% \pm 6.84 \%$ in the 5-FU group, and $63.76 \% \pm 8.58 \%$ in the combined group after treatment for 48 hours. These results suggest that NVP-BEZ235 enhances the chemosensitivity of gastric cancer cells to 5-FU.

\section{NVP-BEZ235 enhances 5-FU-induced apoptosis of MKN-45 cells}

Flow cytometric analysis showed that the apoptosis rate was $6.40 \% \pm 0.70 \%$ in the control group, $11.07 \% \pm 2.00 \%$ in the
NVP-BEZ235 group, $21.33 \% \pm 1.31 \%$ in the 5 -FU group, and $34.81 \% \pm 3.44 \%$ in the combined group (Figure 1). The apoptosis rate of the combined group was significantly lower than that of the 5-FU group $(P<0.05)$. These results suggest that NVP-BEZ235 enhances 5-FU-induced apoptosis in gastric cancer cells.

\section{NVP-BEZ235 inhibits the migration and invasion of MKN-45 cells}

An in vitro cell migration assay showed that the number of migrated cells in the NVP-BEZ235 group (220.33 \pm 4.93$)$ was significantly lesser than in the control group (283.67 \pm 17.62 ; $P<0.05)$. The number of migrated cells in the combined group (121.67 \pm 8.50$)$ was significantly less than in the 5-FU group (151.67 $\pm 9.61 ; P<0.05$; Figure $2 \mathrm{~A}-\mathrm{D})$. An in vitro cell invasion assay showed that the number of invaded cells in the

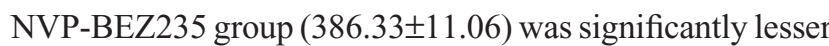
than in the control group $(438.33 \pm 15.50 ; P<0.05)$. The num-

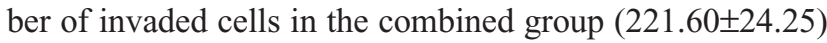
was significantly lesser than in the 5-FU group (286.67 \pm 27.50 ; $P<0.05$; Figure 2E-H). These data indicate that NVPBEZ235 inhibits the migration and invasion of gastric cancer cells and enhances the inhibitory effects of 5-FU on the migration and invasion of gastric cancer cells.

\section{NVP-BEZ235 modulates the expression of apoptosis-related proteins in MKN-45 cells}

To understand how NVP-BEZ235 promotes 5-FU-induced apoptosis of gastric cancer cells, we detected the expression of apoptosis-related proteins in MKN-45 cells treated with NVP-BEZ235 and/or 5-FU. Western blotting analysis showed that the relative expression levels of cleaved caspase- 3 and Bax increased in both the NVP-BEZ235 and 5-FU groups as compared to the control group, and further increased in the combined group. In contrast, the relative expression levels of Bcl-2 decreased in both the NVP-BEZ235 and 5-FU groups as compared to the control group, and further decreased in the combined group (Figure 3). These results suggest that NVP-BEZ235 enhances the expression of pro-apoptotic proteins, whereas it inhibits the expression of anti-apoptotic proteins to promote chemotherapy-induced apoptosis in gastric cancer cells.

\section{NVP-BEZ235 and 5-FU inhibit the growth of $\mathrm{MKN}-45$ cells in vivo}

To confirm the antitumor effects of NVP-BEZ235 in vivo, we established a xenograft mouse model of a tumor derived from MKN-45 cells. The tumor growth curve showed that 
A

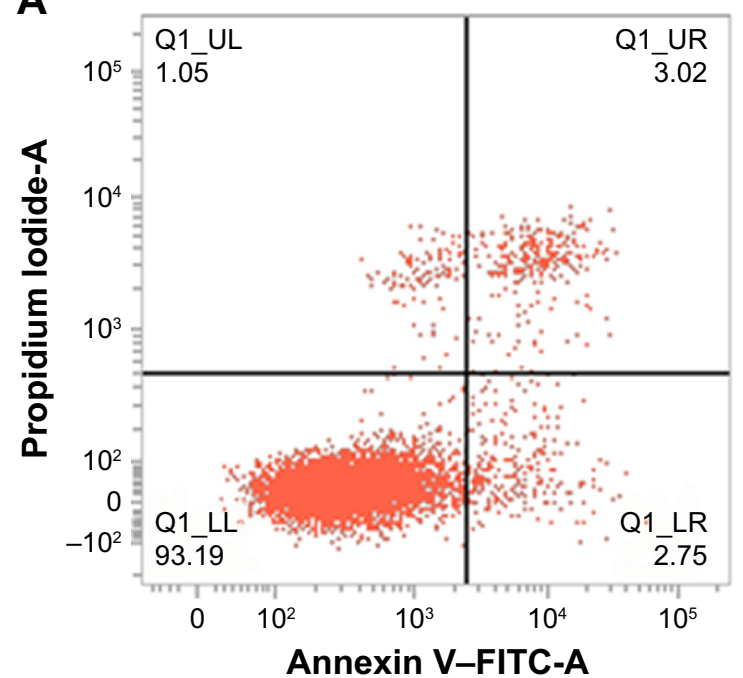

C

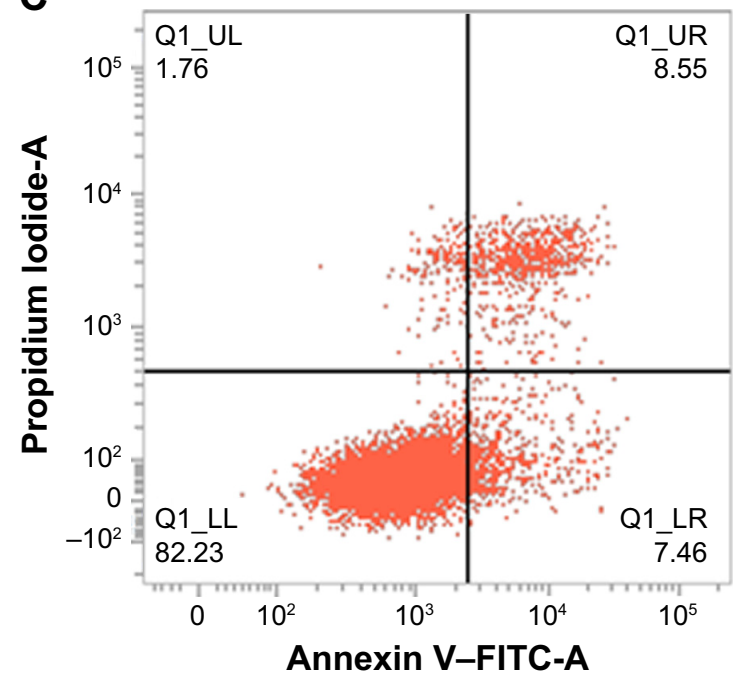

B

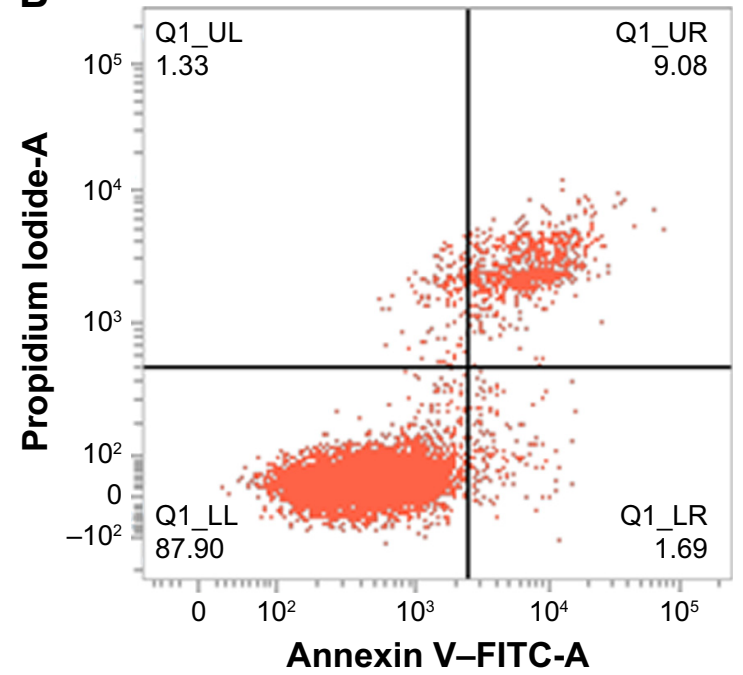

D

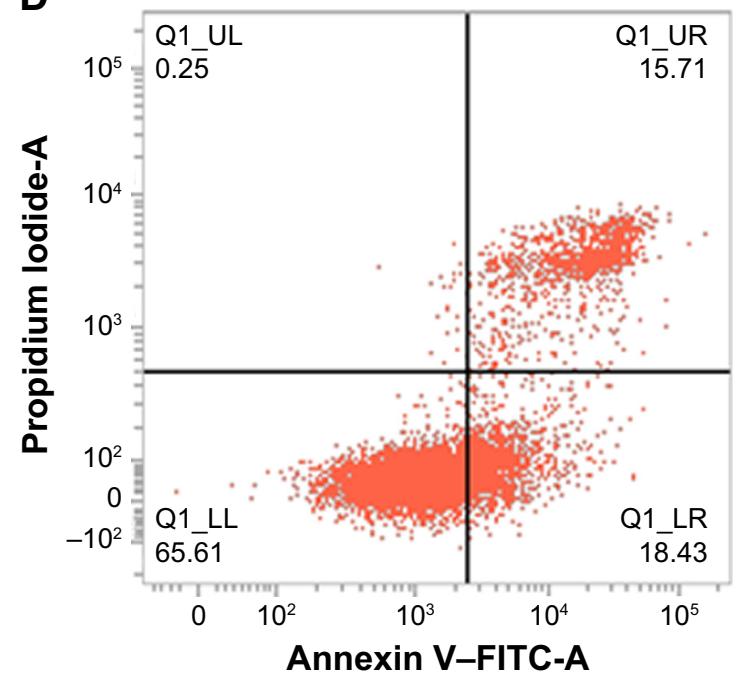

Figure I Apoptosis of gastric cancer MKN-45 cells in each group.

Note: (A) Control group, (B) NVP-BEZ235 treatment group, (C) 5-FU treatment group, and (D) combined treatment group.

the growth of xenografted tumor decreased in both the NVP-BEZ235 and 5-FU groups, respectively, and further decreased in the combined group (Figure 4). Moreover, the tumor weight in NVP-BEZ235 group $(1.58 \pm 0.23 \mathrm{~g})$ was lower than that in the control group $(1.67 \pm 0.37 \mathrm{~g})$; nevertheless, the difference was not statistically significant $(P>0.05)$. However, tumor weight in the combined group $(0.83 \pm 0.16 \mathrm{~g})$ was significantly lower than that in 5-FU group $(1.20 \pm 0.32 \mathrm{~g}$; $P<0.05)$. These data suggest that NVP-BEZ235 enhances the chemotherapeutic effect on gastric cancer in vivo.

NVP-BEZ235 modulates the expression of cancer-related proteins in tumor xenograft

Finally, we investigated the molecular mechanism by which NVP-BEZ235 enhances chemotherapy of gastric cancer in vivo. As NVP-BEZ235 is a dual inhibitor of Akt and
mTOR, we detected the activation of PI3K/Akt $/ \mathrm{mTOR}$ signaling in MKN-45 gastric cancer xenograft. Western blotting analysis showed that NVP-BEZ235 reduced the levels of p-Akt and mTOR alone or in combination with 5-FU (Figure 5A). These results confirm that NVP-BEZ235 inhibited PI3K/Akt/mTOR signaling.

Next, we examined the expression of apoptosis-related proteins in the MKN-45 gastric cancer xenograft. Western blotting analysis showed that NVP-BEZ235 decreased the levels of Bcl-2 but increased the levels of Bax and cleaved caspase-3, either alone or in combination with 5-FU (Figure 5B). Furthermore, we examined the expression of metastasis-related proteins in MKN-45 gastric cancer xenograft. Western blotting analysis showed that NVP-BEZ235 decreased the levels of MMP9 and VEGF alone or in combination with 5-FU (Figure 5C). These results 

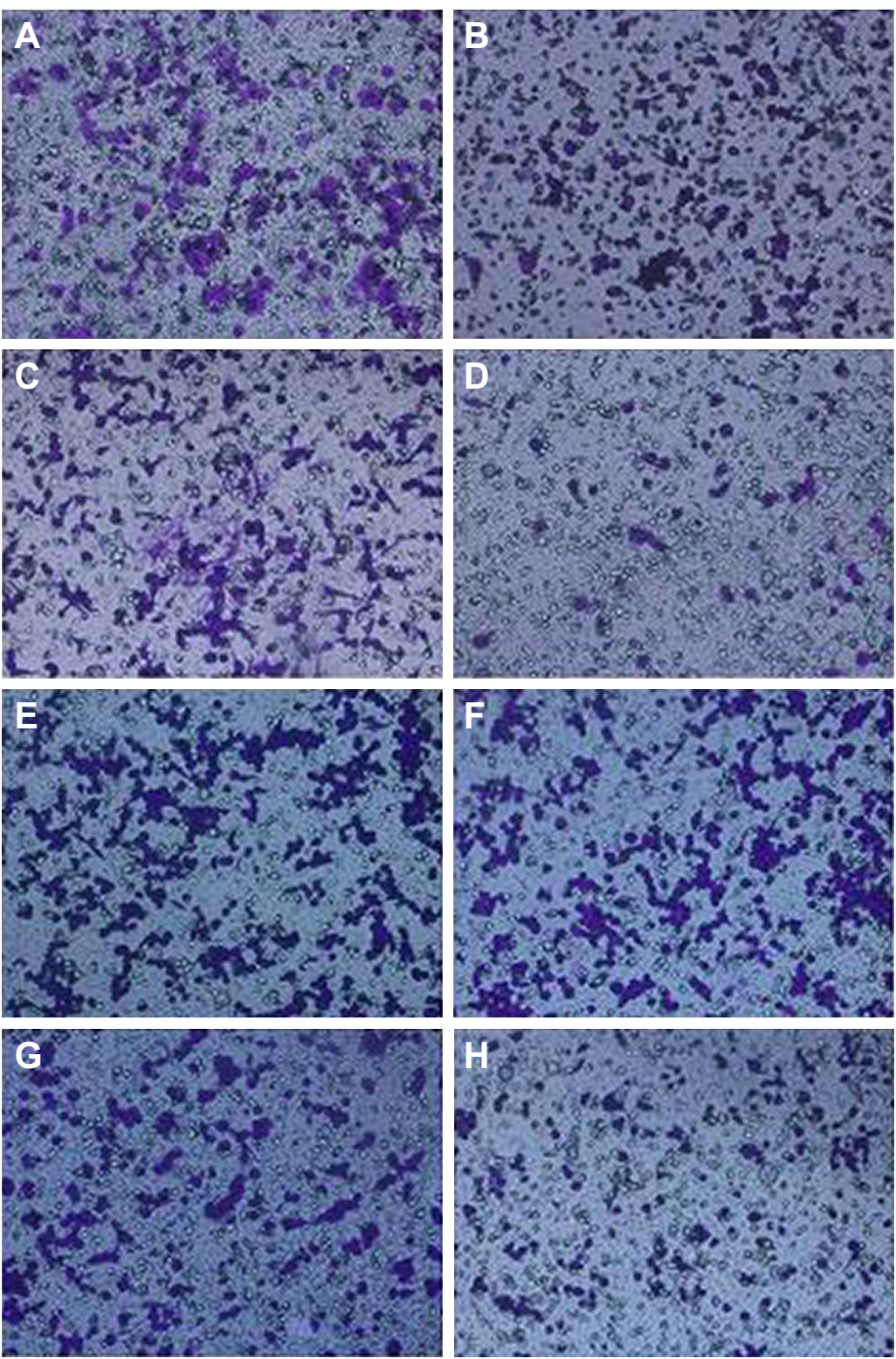

Figure 2 The migration and invasion of gastric cancer MKN-45 cells in each group.

Notes: (A-D) Typical images of migrated cells. (E-H) Typical images of invaded cells. A, E: Control group, B, F: NVP-BEZ235 treatment group, C, G: 5-FU treatment group, D, H: Combined treatment group. Magnification: $\times 200$.

suggest that NVP-BEZ235 induced apoptosis and inhibited the metastasis of gastric cancer.

\section{Discussion}

Zhu et al found that NVP-BEZ235 inhibited the proliferation of gastric cancer cells by blocking the cell cycle at the G1 phase in vitro in a dose-dependent manner. ${ }^{12}$ Previous studies suggest that abnormal activation of PI3K/Akt/mTOR pathway is an important cause of the resistance to chemotherapy in tumors. ${ }^{13}$ In this study, we conducted both in vitro and in vivo experiments to demonstrate that NVP-BEZ235 could inhibit the activation of the PI3K/Akt/mTOR signaling pathway in gastric cancer and increase the chemotherapeutic efficacy of 5-FU. These results are consistent with the previously reported efficacy of NVP-BEZ235 in colon cancer, pancreatic cancer, and other malignant tumor cells. ${ }^{14-17}$

In particular, we validated the efficacy of NVP-BEZ235 in a gastric cancer xenograft model in nude mice. In the in vivo animal model, we found that NVP-BEZ235 treatment alone led to no significant decrease in tumor volume and weight of xenograft when compared to the control group, suggesting that NVP-BEZ235 in itself has a weak antitumor effect. However, combined use of NVP-BEZ235 with 5-FU could significantly inhibit the growth of the xenografted tumor. In addition, we confirmed that NVP-BEZ235 and 5-FU synergistically inhibited the activation of the PI3K/Akt/mTOR 


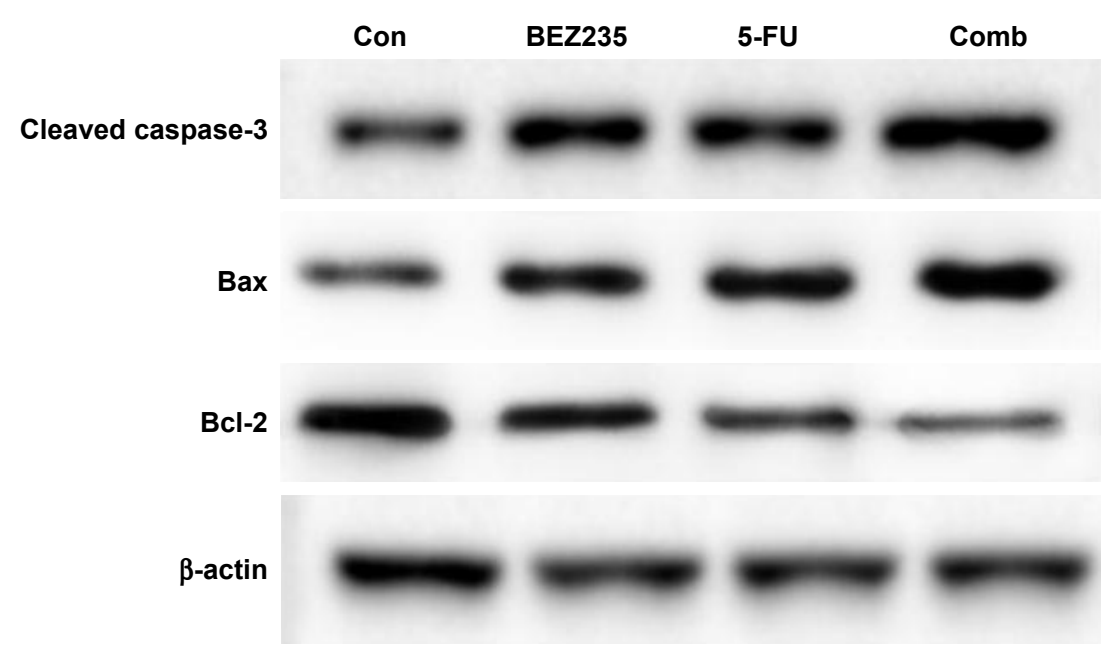

Figure 3 Western blotting analysis of the levels of apoptosis-related proteins in gastric cancer MKN-45 cells in each group. Abbreviations: 5-FU, 5-FU treatment group; BEZ235, NVP-BEZ235 treatment group; Comb, combined treatment group; Con, control group.

signaling pathway in the xenografted tumor. These results indicate that NVP-BEZ235 could enhance the sensitivity of gastric cancer to chemotherapeutic drugs by inhibiting abnormal activation of the PI3K/Akt/mTOR pathway.

Induction of apoptosis is an important mechanism through which cytotoxic drugs kill cancer cells. ${ }^{18}$ Caspase-3 is the main executor of apoptosis, and its action is regulated by anti-apoptotic factors such as Bcl-2 and pro-apoptotic factors such as Bax. ${ }^{19}$ Both Bcl-2 and Bax play very important roles in apoptosis, particularly in the mitochondrial pathway. Several studies have reported the modulation of cancer cell apoptosis via the mitochondrial pathway by combinational treatment. ${ }^{20-23}$ In this study, we detected the expression of apoptosis-related proteins in gastric cancer cells - both in vitro and in vivo. The results showed that NVP-BEZ235 and 5-FU could induce the apoptosis of gastric cancer cells, and combination therapy could enhance this induction of apoptosis, suggesting that NVP-BEZ235 and 5-FU have a synergistic effect to induce gastric cancer cell apoptosis, in agreement with previous studies. ${ }^{24-26}$

Invasion and metastasis are important causes of the failure of malignant tumor treatment. In our study, we conducted a Transwell assay to examine the migration and invasion of gastric cancer cells in vitro. In the animal model experiment, we detected VEGF and MMP9 expression levels to determine the ability of invasion and metastasis in xenografted tumors. Both VEGF and MMP9 play important roles in tumor infiltration and metastasis. VEGF expression is positively correlated with angiogenesis, and VEGF can be used as a valuable biological indicator of tumor invasion. ${ }^{27}$ We found that NVP-BEZ235 significantly reduced the number of migratory and invasive cells and inhibited the expression of VEGF and MMP9, suggesting that NVP-BEZ235 can inhibit gastric cancer invasion in combination with 5-FU. The mechanism underlying this

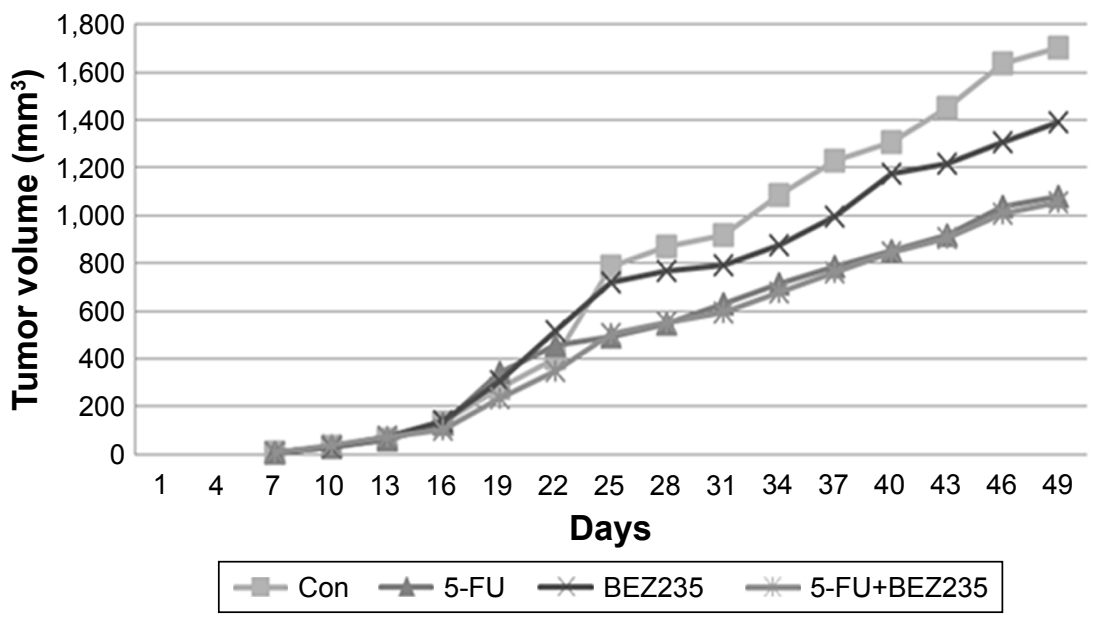

Figure 4 The growth curve of gastric cancer MKN-45 cells xenografted in nude mice in each group.

Abbreviations: 5-FU, 5-FU treatment group; 5-FU+BEZ235, combined treatment group; BEZ235, NVP-BEZ235 treatment group; Con, control group. 
A

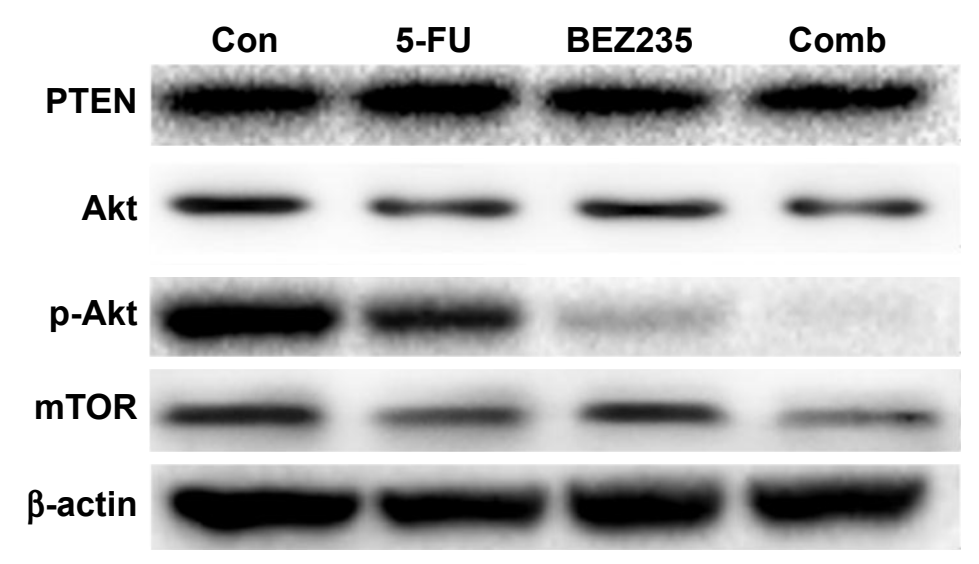

B

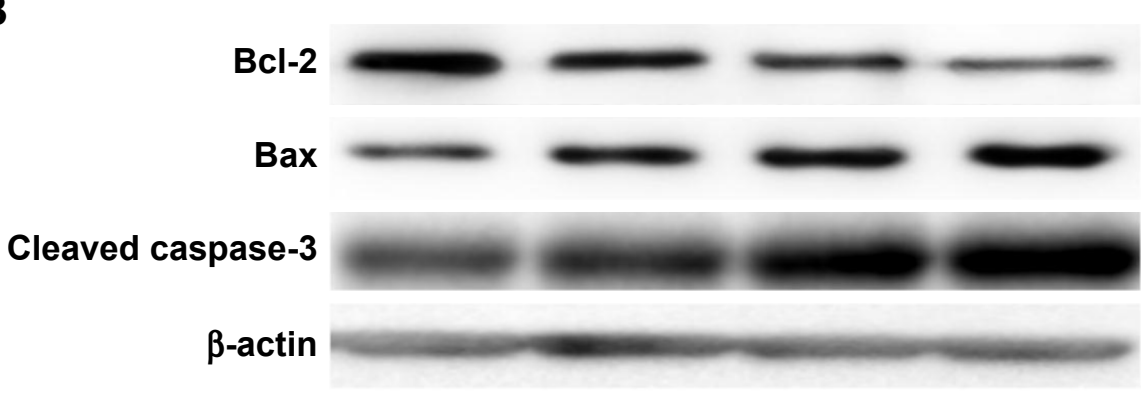

C

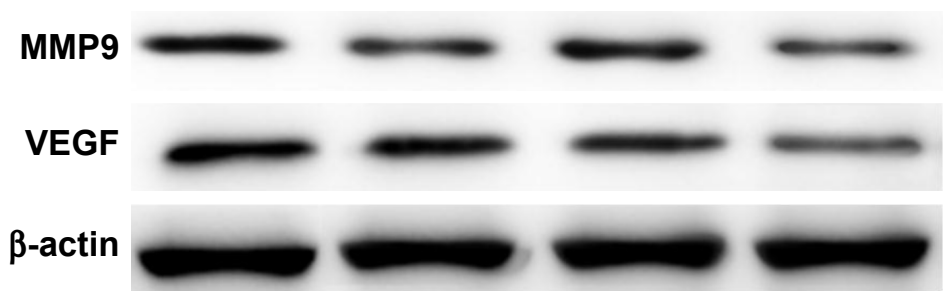

Figure 5 Western blotting analysis of protein levels in xenografts in each group.

Notes: (A) Akt/mTOR-related proteins. (B) Apoptosis-related proteins. (C) Metastasis-related proteins.

Abbreviations: 5-FU, 5-FU treatment group; BEZ235, NVP-BEZ235 treatment group; Comb, combined treatment group; Con, control group.

may be that, upon PI3K/Akt/mTOR pathway activation, the mTOR C1 complex promotes mRNA translation of 4EBP1 and p70S6K, which then upregulates the expression of MMPs and enhances tumor invasion. ${ }^{28}$

\section{Conclusion}

In summary, we demonstrate that NVP-BEZ235 inhibited the activation of the PI3K/Akt/mTOR pathway, promoted apoptosis, and inhibited the proliferation and invasion of gastric cancer cells. More importantly, NVP-BEZ235 enhanced the antitumor efficacy of 5-FU. Therefore, NVP-BEZ235 is a promising agent to enhance chemotherapy for gastric cancer.

\section{Data sharing statement}

Request for any data generated in this study can be obtained from the corresponding author, Dr Dun Pan.

\section{Acknowledgments}

This study was supported by the National Key Clinical Specialist Construction Programs of China, Fujian Provincial Natural Science Foundation Projects (grant nos 2016J01447, 2017J01287), and the Fujian Provincial medical innovation project (grant no 2015-CX-23).

\section{Disclosure}

The authors report no conflicts of interest in this work.

\section{References}

1. Lin Y, Ueda J, Kikuchi S, et al. Comparative epidemiology of gastric cancer between Japan and China. World J Gastroenterol. 2011;17(39): 4421-4428.

2. Sasako M, Sano T, Yamamoto S, et al; Japan Clinical Oncology Group. D2 lymphadenectomy alone or with para-aortic nodal dissection for gastric cancer. N Engl J Med. 2008;359(5):453-462. 
3. Ding S, Xiong J, Lei D, Zhu XL, Zhang HJ. Recombinant nanocomposites by the clinical drugs of Abraxane and Herceptin as sequentially dual-targeting therapeutics for breast cancer. J Cancer. 2018;9(3): 502-511.

4. Wang TE, Wang YK, Jin J, Xu BL, Chen XG. A novel derivative of quinazoline, WYK431 induces G2/M phase arrest and apoptosis in human gastric cancer BGC823 cells through the PI3K/Akt pathway. Int J Oncol. 2014;45(2):771-781.

5. Kuete V, Saeed ME, Kadioglu O, et al. Pharmacogenomic and molecular docking studies on the cytotoxicity of the natural steroid wortmannin against multidrug-resistant tumor cells. Phytomedicine. 2015;22(1): $120-127$.

6. Zhou Y, Zhu LB, Peng AF, et al. LY294002 inhibits the malignant phenotype of osteosarcoma cells by modulating the phosphatidylinositol 3-kinase/Akt/fatty acid synthase signaling pathway in vitro. Mol Med Rep. 2015;11(2):1352-1357.

7. Stein RC. Prospects for phosphoinositide 3-kinase inhibition as a cancer treatment. Endocr Relat Cancer. 2001;8(3):237-248.

8. Yao M, Shang YY, Zhou ZW, et al. The research on lapatinib in autophagy, cell cycle arrest and epithelial to mesenchymal transition via Wnt/ErK/PI3K-AKT signaling pathway in human cutaneous squamous cell carcinoma. J Cancer. 2017;8(2):220-226.

9. O'Brien NA, Mcdonald K, Tong L, et al. Targeting PI3K/mTOR overcomes resistance to HER2-targeted therapy independent of feedback activation of AKT. Clin Cancer Res. 2014;20(13):3507-3520.

10. Oishi T, Itamochi $\mathrm{H}$, Kudoh $\mathrm{A}$, et al. The PI3K/mTOR dual inhibitor NVP-BEZ235 reduces the growth of ovarian clear cell carcinoma. Oncol Rep. 2014;32(2):553-558.

11. Awasthi N, Yen PL, Schwarz MA, Schwarz RE. The efficacy of a novel, dual PI3K/mTOR inhibitor NVP-BEZ235 to enhance chemotherapy and antiangiogenic response in pancreatic cancer. J Cell Biochem. 2012; 113(3):784-791.

12. Zhu Y, Tian T, Zou J, et al. Dual PI3K/mTOR inhibitor BEZ235 exerts extensive antitumor activity in HER2-positive gastric cancer. $B M C$ Cancer. 2015;15:894.

13. Zhou B, Sun C, Li N, et al. Cisplatin-induced CCL5 secretion from CAFs promotes cisplatin-resistance in ovarian cancer via regulation of the STAT3 and PI3K/Akt signaling pathways. Int J Oncol. 2016;48(5): 2087-2097.

14. Chaisuparat R, Hu J, Jham BC, Knight ZA, Shokat KM, Montaner S. Dual inhibition of PI3 Kalpha and mTOR as an alternative treatment for Kaposi's sarcoma. Cancer Res. 2008;68(20):8361-8368.

15. Serra V, Markman B, Scaltriti M, et al. NVP-BEZ235, a dual PI3K/ mTOR inhibitor, prevents PI3K signaling and inhibits the growth of cancer cells with activating PI3K mutations. Cancer Res. 2008;68(19): $8022-8030$
16. Cao P, Maira SM, García-Echeverría C, Hedley DW. Activity of a novel, dual PI3-kinase/mTor inhibitor NVP-BEZ235 against primary human pancreatic cancers grown as orthotopic xenografts. Br J Cancer. 2009;100(8):1267-1276.

17. Yu Y, Yu X, Ma J, Tong Y, Yao J. Effects of NVP-BEZ235 on the proliferation, migration, apoptosis and autophagy in HT-29 human colorectal adenocarcinoma cells. Int J Oncol. 2016;49(1):285-293.

18. Podratz JL, Knight AM, Ta LE, Le T, et al. Cisplatin induced mitochondrial DNA damage in dorsal root ganglion neurons. Neurobiol Dis. 2011;41(3):661-668.

19. Altieri DC. The molecular basis and potential role of survivin in cancer diagnosis and therapy. Trends Mol Med. 2001;7(12):542-547.

20. Lin M, Tang S, Zhang C, et al. Euphorbia factor L2 induces apoptosis in A549 cells through the mitochondrial pathway. Acta Pharm Sin B. 2017;7(1):59-64.

21. Lin $\mathrm{M}, \mathrm{Bi} \mathrm{H}$, Yan $\mathrm{Y}$, et al. Parthenolide suppresses non-small cell lung cancer GLC-82 cells growth via B-Raf/MAPK/Erk pathway. Oncotarget. 2017;8(14):23436-23447.

22. Zhang JY, Lin MT, Tung HY, et al. Bruceine D induces apoptosis in human chronic myeloid leukemia K562 cells via mitochondrial pathway. Am J Cancer Res. 2016;6(4):819-826.

23. Zhang JY, Lin MT, Zhou MJ, et al. Combinational Treatment of Curcumin and Quercetin against Gastric Cancer MGC-803 Cells in Vitro. Molecules. 2015;20(6):11524-11534.

24. Fazio N, Buzzoni R, Baudin E, et al. A Phase II Study of BEZ235 in Patients with Everolimus-resistant, Advanced Pancreatic Neuroendocrine Tumours. Anticancer Res. 2016;36(2):713-719.

25. Hall CP, Reynolds CP, Kang MH. Modulation of Glucocorticoid Resistance in Pediatric T-cell Acute Lymphoblastic Leukemia by Increasing BIM Expression with the PI3K/mTOR Inhibitor BEZ235. Clin Cancer Res. 2016;22(3):621-632.

26. Sweetlove M, Wrightson E, Kolekar S, et al. Inhibitors of pan-PI3K Signaling Synergize with BRAF or MEK Inhibitors to Prevent BRAFMutant Melanoma Cell Growth. Front Oncol. 2015;5:135.

27. E J, Xing J, Gong H, He J, Zhang W. Combine MEK inhibition with $\mathrm{PI} 3 \mathrm{~K} / \mathrm{mTOR}$ inhibition exert inhibitory tumor growth effect on KRAS and PIK3CA mutation CRC xenografts due to reduced expression of VEGF and matrix metallopeptidase-9. Tumour Biol. 2015;36(2): 1091-1097.

28. Laplante M, Sabatini DM. mTOR signaling in growth control and disease. Cell. 2012;149(2):274-293.
OncoTargets and Therapy

\section{Publish your work in this journal}

OncoTargets and Therapy is an international, peer-reviewed, open access journal focusing on the pathological basis of all cancers, potential targets for therapy and treatment protocols employed to improve the management of cancer patients. The journal also focuses on the impact of management programs and new therapeutic agents and protocols on

\section{Dovepress}

patient perspectives such as quality of life, adherence and satisfaction The manuscript management system is completely online and includes a very quick and fair peer-review system, which is all easy to use. Visit http://www.dovepress.com/testimonials.php to read real quotes from published authors. 